\title{
Mucinous Carcinoma of the breast: Mammography and Ultrasound Appearance with Histopathology Correlation
}

\author{
Ranveer S Ajimal ${ }^{1}$, Biren A Shah ${ }^{2 *}$ and Dongping Shi ${ }^{2}$ \\ ${ }^{1}$ Grand Blanc High School, USA \\ ${ }^{2}$ Detroit Medical Center Sinai Grace Hospital, USA
}

Submission: February 19, 2019; Published: February 26, 2019

*Corresponding author: Biren A Shah, Detroit Medical Center Sinai Grace Hospital 6701 W. Outer Drive, Detroit, Michigan 48235, USA

\begin{abstract}
Mucinous carcinoma, additionally known as colloid carcinoma, is a tumor which consists of abnormal cells in mucus. Manifesting in the milk duct, the mucin serves as a pool where the abnormal cells reside. Mucinous carcinoma can be detected on mammography as well as other imaging modalities [1]. The purpose of this report is to present a case example of this type of breast tumor on mammography and ultrasound with histopathology correlation.
\end{abstract}

Keywords: Mucinous carcinoma; Colloid carcinoma; Mammography; Breast ultrasound

\section{Introduction}

Mucinous carcinoma is a fairly uncommon and a slow growing form of breast cancer, occurring in less than $10 \%$ of all breast malignancies. Patients with this disease range from ages 48 to 82. The pure type is more common in postmenopausal women, whereas the mixed variation is more prevalent in young women. Moreover, in terms of prognosis, patients tend to do better with treatment. In addition, the cancer does not metastasize to other parts of the body nor lymph nodes [2].

Clinically, mucinous carcinoma of the breast is palpable in $50 \%$ of patients and when large can be fixed to skin or chest wall [3]. Mucinous carcinoma can be detected on various imaging modalities. When diagnosing the carcinoma, between breast ultrasound, surgical biopsy, and mammography, mammography is the most prevalent method of diagnosis [2].

Histopathology images: Microscopically, there are large extracellular mucin pools dissecting the breast parenchyma. Floating within the mucin pools are atypical epithelial cells in patterns of acinus, fused glands or nests with ill-defined lumens. Those epithelial cells demonstrate relatively uniform nuclei, distinct nucleoli and scant amount of cytoplasm.

\section{Case Study}

73 year-old female with a palpable lump in the right breast for the past 2 months (Figure 1-6).
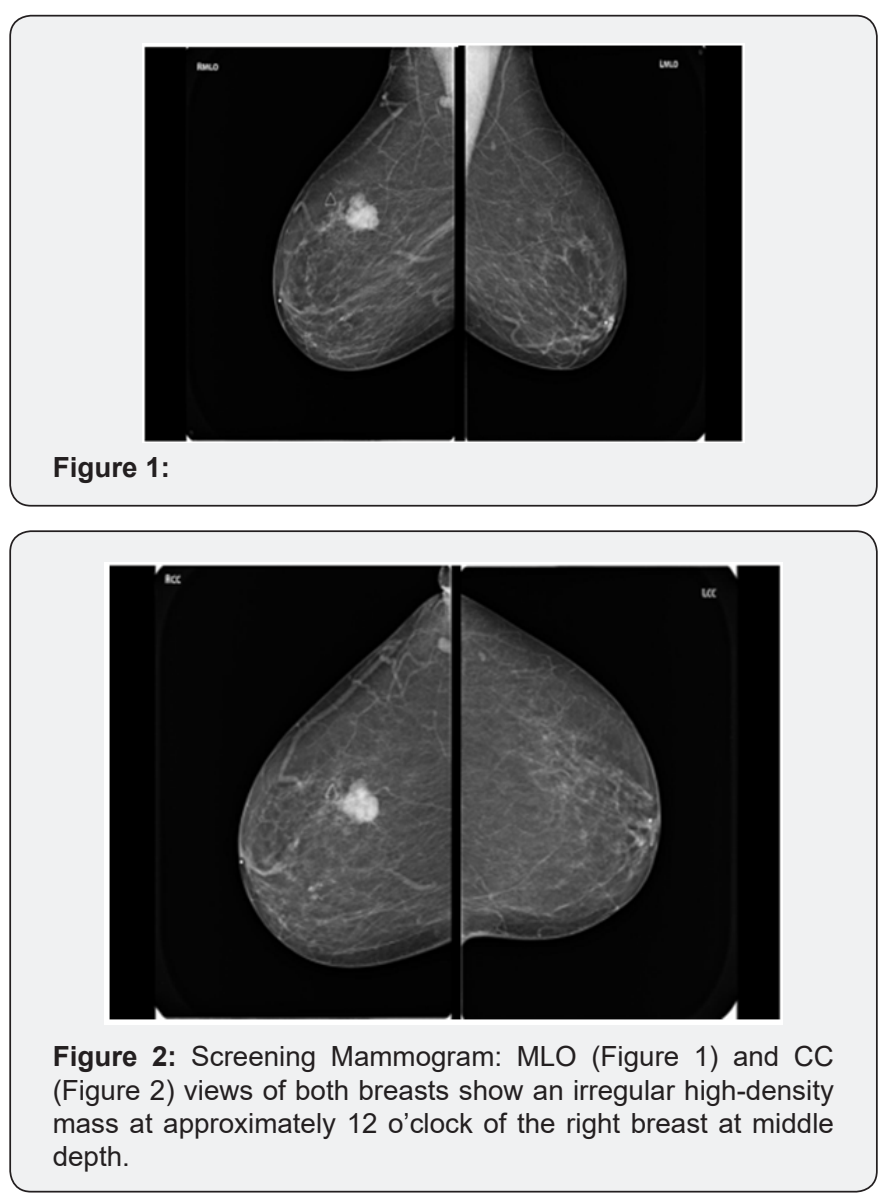


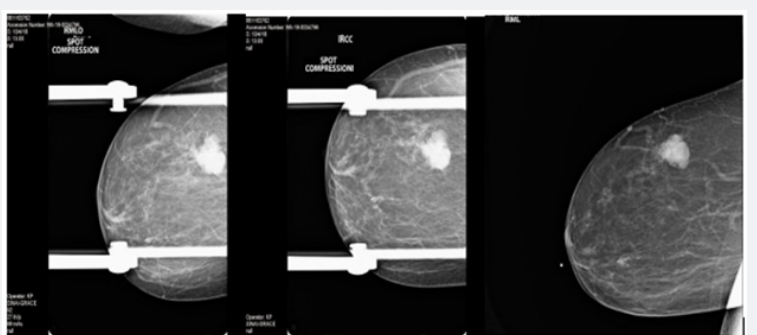

Figure 3: Diagnostic Mammogram: Spot compression mediolateral oblique, spot compression craniocaudal, and mediolateral views of the right breast demonstrate an irregular high-density mass with indistinct and microlobulated margins at approximately 12 o'clock middle depth.

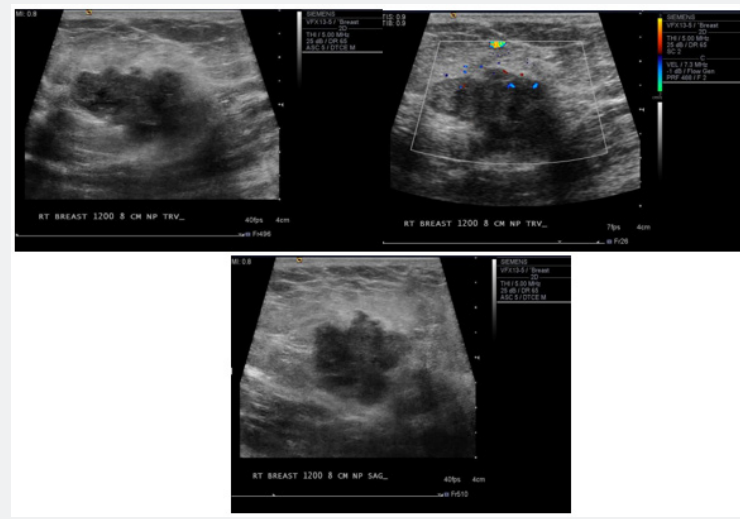

Figure 4: Diagnostic targeted right breast ultrasound: On ultrasound there is an irregular solid hypoechoic mass with angular margins at 12 o'clock at a distance of $8 \mathrm{~cm}$ from the nipple.

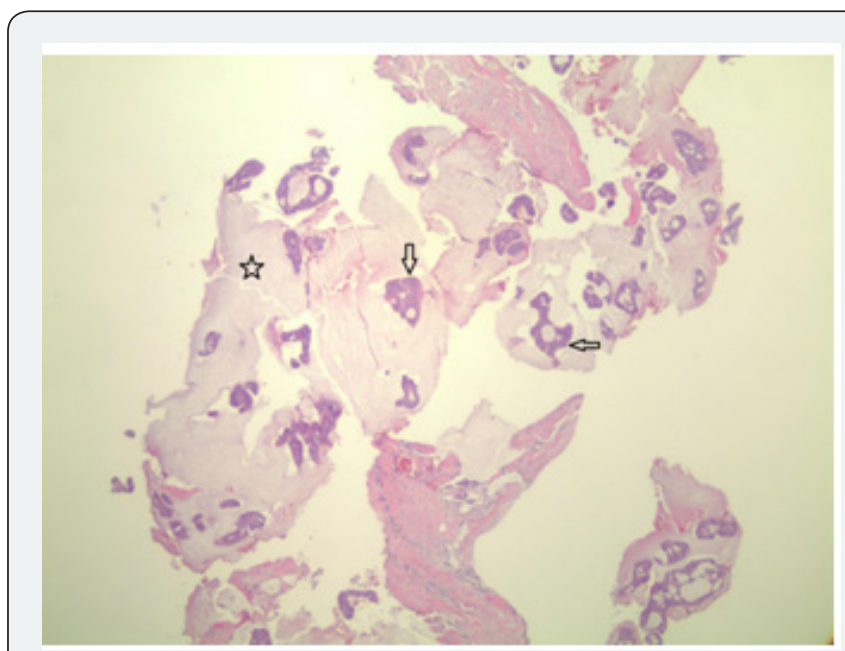

Figure 5: Microphotograph of mucinous carcinoma (40x). Clusters of atypical epithelial cells (arrows) are see floating within large extracellular mucin pools (star).

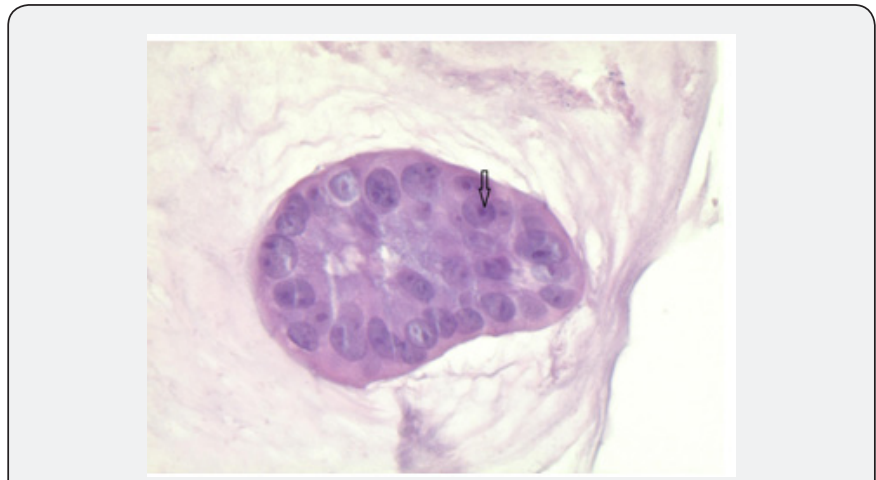

Figure 6: Microphotograph of mucinous carcinoma (400x). A distinct nucleoli is indicated by an arrow.

\section{Discussion}

Mucinous carcinoma is a rare tumor that resides in pools of mucin and occurs in less than $10 \%$ of all other breast carcinoma. The tumor rarely metastasizes to axillary lymph nodes. Clinically, this disease is palpable in $50 \%$ of patients and can be fixed to the chest wall or skin when the tumor is large enough. There are two histologic types of mucinous carcinoma, pure and mixed. The pure type has tissue with extracellular mucin production and represents $2 \%$ of all malignant breast neoplasms. The mixed form of mucinous carcinoma of the breast encompasses an invasive ductal epithelial component which does not contain mucus [4]. This tumor can be identified on mammography, ultrasound, and MRI.

On mammography, the appearance of pure and mixed mucinous carcinoma is different. Pure mucinous carcinoma is usually round or oval in shape. In addition, its margins are usually circumscribed due to their rapid growth pattern. The mixed form typically presents as an irregular mass with spiculated or indistinct margins, no matter the tumor size, because of the lack of the mucinous component creating a fibrotic appearance [5]. Microcalcifications are rare; although, when present, it is amorphous, round, and/or rarely pleomorphic [6].

On ultrasound, the mixed type of mucinous carcinoma may appear as a complex solid and cystic mass. This lesion may be difficult to spot if it is isoechoic to fat, especially when small $(\leq 1.5 \mathrm{~cm})$. The pure type of mucinous carcinoma is iso-echogenic due to the fat surrounding the breast tissue as visualized on the ultrasound. Homogeneity of the mass is usually seen with the pure type of mucinous carcinoma. Posterior enhancement is found in mucinous carcinoma in more than $50 \%$ of cases [3].

On T1-weighted MRI sequences, mucinous carcinoma has low signal intensity. On T2-weighted sequences, mucinous carcinoma is of high signal intensity due to a large mucin content. Mucinous carcinoma is hyperintense on DWI, diffusion weighted images, with high ADC, apparent diffusion coefficient, values. On 
post contrast T1-weighted fat-saturation images, there is avid rim enhancement with a persistent or plateau kinetic curve [3].

Histologically, $50-80 \%$ of all breast cancer are invasive carcinoma of no special type. Mucin production can be seen intracellular and extracellular. By WHO definition [7], "mucinous carcinoma is characterized by clusters of generally small and uniform cells floating in large amount of extracellular mucin". Pure mucinous carcinoma is defined as more than $90 \%$ of the tumor growing in aforementioned pattern. Mixed mucinous carcinoma is most commonly mixed with invasive carcinoma of no special type. Typically, mucinous carcinoma expresses estrogen and progesterone receptors and lack of HER2 amplification.

Pure mucinous carcinoma of the breast has low incidence of extensive intraductal spreading. Anan et al. [8] found situations of lymphatic vessel invasion and nodal involvement to be higher in mixed mucinous carcinoma than in the pure type. Nodal involvement did not appear in patients who had pure mucinous carcinoma with a diameter less than 3 centimeters. Patients with the pure type of mucinous carcinoma are more suitable to treatment as compared to patients with the mixed type. Treatment for this disease is commonly a lumpectomy; however, a sentinel axillary lymph node biopsy may be executed. After a lumpectomy, radiation therapy is performed. A mastectomy is implemented if the tumor is large or if there is multicentricity.
Chemotherapy treatment is based on tumor size and nodal status. The 10-year survival rate for pure mucinous carcinoma is $90 \%$. Survival rate for mixed form of mucinous carcinoma is similar to invasive ductal carcinoma, not otherwise specified [8].

\section{References}

1. Shah B, Fundaro G, Mandava S (2015) Breast Imaging Review: A Quick Guide to Essential Diagnoses. (2 $\left.{ }^{\text {nd }} e d n\right)$, Springer, USA, pp. 295-298.

2. Ha KY, DeLeon P, DeLeon W (2013) Invasive mucinous carcinoma of the breast. Proc (Bayl Univ Med Cent) 26(3): 295-297.

3. Berg W, Yang W (2014) Diagnostic Imaging: Breast. ( $2^{\text {nd }}$ edn) Amirsys Inc, USA, 5: 250-255.

4. Al Haddad H, Awadallah A, Abdel Hadi (2017) Mucinous breast carcinoma: Report of four cases and review of the literature. Clin Diagn Pathol Volume 1(4): 1-4.

5. Wilson TE, Helvie MA, Oberman HA, Joynt LK (1995) Pure and mixed mucinous carcinoma of the breast: pathologic basis for differences in mammographic appearance. AJR Am J Roentgenol 165(2): 285-289.

6. Wilson D, Kalisher L, Port J, Titus J, Kirzner H (1997) Breast Imaging Case of the Day. RadioGraphics 17(3): 800-804

7. (2012) WHO Classification of Tumors of the Breast, ( $4^{\text {th }}$ edn).

8. Anan K, Mitsuyama S, Tamae K, Nishihara K, Iwashita T, et al. (2001) Pathological features of mucinous carcinoma of the breast are favourable for breast-conserving therapy. European Journal of Surgical Oncology 27(5): 459-463.
This work is licensed under Creative Commons Attribution 4.0 License DOI: 10.19080/JOJCS.2019.09.555774
Your next submission with Juniper Publishers will reach you the below assets

- Quality Editorial service

- Swift Peer Review

- Reprints availability

- E-prints Service

- Manuscript Podcast for convenient understanding

- Global attainment for your research

- Manuscript accessibility in different formats ( Pdf, E-pub, Full Text, Audio)

- Unceasing customer service

Track the below URL for one-step submission https://juniperpublishers.com/online-submission.php 